\title{
Development Status of College Aesthetic Education and Corresponding Teaching Strategies from the Perspective of New Media
}

Jin Xin

School of Art and Design, Bengbu University, 233000 Bengbu, Anhui, China

\begin{abstract}
With the vigorous development of new media, aesthetic education plays a pivotal role as a vital and necessary link for the development of quality-oriented education in colleges and universities. However, colleges and universities nowadays value knowledge education more than aesthetic education, aesthetic education curriculum remains to be diversified and enriched, and aesthetic education practice activities tend to be in a superficial form, all of which have turned aesthetic education into an obstacle affecting the overall development of college students. We should practically grasp the development status and problems of college aesthetic education, and systematically analyze the reasons of such problems, which is of great practical significance for the establishment and development of contemporary aesthetic education curriculum system.
\end{abstract}

\section{Introduction}

The term "aesthetic education" was first proposed by Schiller in his book On the Aesthetic Education of Man. In the middle and later periods of the last century, guided by Marxist theory, an education theorist of the former Soviet Union, refined the principles, methods, tasks and directions of aesthetic education development in Principles of Aesthetic Education, proposing that "the fundamental task of aesthetic education is to cultivate people with rich spirits, noble morals, physical fitness, and comprehensive and harmonious development[1]". In Marxist-Leninist Aesthetics, It stated that aesthetic education aims to cultivate the "comprehensive and harmonious personality" [2].

In China, found in education as early as the pre-Qin period, the aesthetic education system has been constantly developing up to now. Creating a favorable environment for aesthetic education development can purify the minds and cultivate the sentiments of college students, and promote the comprehensive development of college students in all aspects and from multiple angles, thereby contributing to the cultivation of builders and successors who can shoulder heavy responsibilities for the socialist cause.

\section{Realistic Difficulties Faced by Aesthetic Education Development in Contemporary Colleges and Universities}

Related to the quality development level and aesthetic cognitive needs of contemporary people, aesthetic education is closely related to the quality of human life. The importance of aesthetic education is increasingly highlighted in the cultivation of college students' comprehensive quality. However, it is not difficult to find through surveys that aesthetic education appears to be ignored and underestimated in the current education system, especially when it comes to higher education. Preference of knowledge education over aesthetic education is particularly serious, which is extremely detrimental to the all-round development of quality education for contemporary college students.

In recent years, more and more attention has been paid to college aesthetic education, but the effect has not been satisfactory. Based on investigation and analysis, the reasons are roughly divided into the following points (Figure 1):

Problems faced by aesthetic education development in colleges and universities

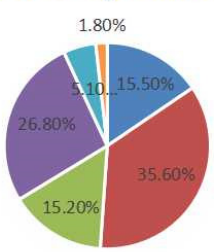

Incomplete evaluation system

- Vacuous content of aesthetic education curriculum

- Insufficient teachers

- Single form of aesthetic education activities

- Insufficient awareness of the importance of aesthetic education

Others

Figure 1. Problems faced by aesthetic education development in colleges and universities

\footnotetext{
*Corresponding author's e-mail: 123241190@qq.com
} 


\subsection{Relatively Weak Aesthetic Cognition of College Students}

Rodin once said, "Beauty is everywhere. To our eyes, it is not lack of beauty, but the a lack of discovery". The so-called cultivation of aesthetic cognition is also to help college teachers and students gain the ability to perceive and discover beauty.

In this regard, a series of surveys have been conducted. According to these surveys, contemporary college students' understanding of beauty is superficial and stays in the primary stage, that is, "whether it is good-looking and popular" is the universal standard for college students to judge if something is beautiful. Their perception and cognition of beauty lies merely on the surface, and the intrinsic beauty of things is seriously ignored. In short, while trying to know the world, college students, as the mainstay of China, have developed relatively weak subjective cognition regarding the comprehension and transmission of beauty, which will seriously restrict the overall improvement of the national quality.

\subsection{Inadequate Aesthetic Education Curriculum and Single Curriculum Content}

The teaching of aesthetic education curriculum is the main transmission form of college aesthetic education, but the surveys show that the teaching system of college aesthetic education still remains to be improved. Many colleges and universities are facing countless problems such as unqualified teachers, inadequate class hours, instability in curriculum settings, outdated and backward teaching methods, and boring curriculum content.

Most colleges and universities only offer elective courses on aesthetic education, and the number of related courses is relatively small. Consequently, the demand exceeds the supply. Many students hope to increase the number of such elective courses. The course content is relatively single, the teaching process is tedious, the aesthetic education curriculum has become a mere formality to some extent, the teaching content is outdated, and aesthetic education is generally theoretical rather than practical and innovative. Besides, inculcating teaching restricts students' creative thinking, which is not conducive to improving the comprehensive quality of contemporary college students.

\subsection{Superficial Form of Aesthetic Education Practical Activities}

There are many ways to implement college aesthetic education. In addition to the most basic aesthetic education curriculum, campus cultural activities and social practice activities have both become chief approaches to enhance college students' aesthetic awareness. Various campus aesthetic education activities, e.g. cultural and artistic performances, theme exhibitions, community activities, essay competitions, volunteer services, public welfare activities and aesthetic education lectures, can unconsciously cultivate the sentiment of college students, broaden their horizons, enrich their knowledge reserves, improve their moral integrity and significantly strengthen their comprehensive quality.

In the implementation of aesthetic education practice activities, without professional guidance, aesthetic education activities have become formalistic, with the teaching content being superficial, the teaching form being single, and relevant courses being dull and boring. It has blurred the value orientation of aesthetic education as well as hindered the development and implementation of aesthetic education practice activities for college students, which restricts the healthy development of college aesthetic education to some extent.

\section{Reasons for Difficulties in Development of College Aesthetic Education}

\subsection{Influence of Mass Media on Aesthetic Cognition of Contemporary College Students}

With the rapid development of the market economy, mass media, as a product of modern industrialization, uses media like WeChat, QQ, Weibo, TV, radio and movies to obtain information in an intuitive and easy-to-understand way of expression, providing audiences with rich perceptual cognition and aesthetic taste. Diversified channels of information communication are actually a double-edged sword. During information communication, some information that misleads the public's aesthetics and pollutes the social environment might also be transmitted. College students have neither completely established a rational aesthetic value recognition system, nor abandoned the bad and vulgar information from the root of their thinking, invisibly hindering the formation of contemporary college students' aesthetic cognition and value orientation. A series of trendy thinking and cognitions such as disapproval of traditional culture and blind faith in foreign things are the result of the lack of aesthetic theory and cognition, which seriously distort the aesthetic cognition of college students and hinder the development of college students' aesthetic education.

\subsection{Influence of Higher Education on Aesthetic Cognition of Contemporary College Students}

Higher education, as an important part of the nation's cultivation of talents, is a critical platform to carry out aesthetic education for college students. Under the Chinese-style education system that comprehensively promotes comprehensive quality, the inculcating teaching method is generally used to facilitate the college students' understanding of the basic knowledge of aesthetic education. This teaching method helps college students to certain aesthetic theoretical attainment, but it is difficult to fundamentally improve their aesthetic cognition, and the single form of aesthetic education is not conducive to the development of college students' aesthetic value. 
As the most common and conventional teaching mode in the current stage, classroom teaching is the main communication form of aesthetic education. Nonetheless, it is not difficult to find that college aesthetic education courses are mostly offered as public elective courses, and the small number of courses fails to meet students' demands for aesthetic education. It is important to cope with problems, e.g. the establishment of aesthetic education courses, the outdated, vacuous and unpractical teaching content, the rigid teaching methods and course forms, during the process of aesthetic education.

The original intention of college aesthetic education is to enhance and cultivate the aesthetic cognition of college students, stimulate their yearning and pursuit of beautiful things, and promote their all-round development. Nonetheless, contemporary college students mostly start from their own interests and needs to emphasize the actual effect of aesthetic education and functionalize college aesthetic education, which deviates from the original educational ideas and goals of aesthetic education and hinders the development of aesthetic education.

\section{Teaching Strategies under the Dilemma of College Aesthetic Education}

Mr. Cai Yuanpei once said, "Education is the cause of cultivating personality." The irreplaceable status and role of aesthetic education in higher education cannot be underestimated. Playing an important role in the formation of personality, college aesthetic education is one of the primary approaches to develop personality [3]. The ultimate goal of talent training in universities today is to promote the comprehensive development of contemporary college students.

By analyzing the current dilemma of college aesthetic education and relevant causes, we can easily find the defects of college aesthetic education. The central links of improving aesthetic education include providing content and form of aesthetic education suitable for contemporary education, cultivating high-quality aesthetic education teachers, creating a favorable aesthetic education learning atmosphere, and constructing a harmonious aesthetic education operating mechanism. It is of great importance to establish a complete and multi-dimensional aesthetic education system, make full use of aesthetic education platform in colleges and universities, integrate aesthetic education, knowledge education and social education, and systematically improve the comprehensive quality of college students, so as to ultimately achieve the fundamental goal of aesthetic education.

\subsection{Constructing a Complete Aesthetic Education Curriculum System}

To comprehensively improve the morals and ethics of college students, it is not enough to simply cultivate students' knowledge in a specific professional field. Instead, mastery should be achieved through a comprehensive study of different subjects from multiple perspectives, in the hope of cultivating comprehensive talents that develop in an all-round way. All students should be regarded as the targets to receive aesthetic education, and aesthetic education functional curriculum should be popularized. With improving the comprehensive quality of college students as the basic starting point, and to shape the aesthetic education concept, to cultivate students' aesthetic ability and to improve their aesthetic level as the ultimate goal, creating a complete aesthetic education curriculum system is an important prerequisite for effectively promoting aesthetic education.

\section{2"Diversifying" the Aesthetic Education Model}

First of all, from the perspective of the curriculum system, institutions of higher education are supposed to establish a comprehensive, systematic and orderly curriculum system, optimize the curriculum structure, upgrade traditional education, and construct a diversified education model [4]. In terms of curriculum setting, the integration of public elective and compulsory courses is recommended, which not only guarantees that all the students can study aesthetic courses, but also allows students to further their aesthetic education based on their own interest and aesthetic needs. In addition to the basic aesthetic education curriculum, aesthetic education can also be connected with other subjects such as philosophy, history and mathematics, so that aesthetic education can penetrate into all aspects.

Secondly, when it comes to the teaching methods, the teaching objectives of aesthetic education are not simply to enable students to understand the basic knowledge of aesthetic education, but also to assist students in perceiving, cultivating, discovering and creating beauty. Through a series of practical, creative and interesting education and teaching activities, students can perceive, appreciate and create beauty in practice.

In the end, in terms of the teaching materials, based on the traditional Chinese culture, the practical principles of the theoretical courses should be guaranteed, the theoretical part should go from the easy to the difficult and complicated, and the practicality and readability of aesthetic education courses ought to be combined. It helps contemporary college students cultivate their aesthetic sentiment, improve their aesthetic taste, and develop their ability and confidence of discovering, cognizing, perceiving, tasting and creating beauty [5].

\subsection{Cultivating a Team of High-quality Teachers}

A team of excellent teachers is the most favorable prerequisite to guarantee the normal teaching of relevant courses, so institutions of higher education must train a team of high-quality and high-level teachers to ensure the efficient implementation of aesthetic education courses. College aesthetic education teachers should be equipped with profound knowledge and professional skills related to aesthetic education, enhance students' learning enthusiasm with effective teaching methods, enrich teaching content, improve teaching quality, improve the 
teaching system, and control every aspect of teaching.

As a model of virtue for students, teachers are always the ones to be imitated and learned by students, and the words and deeds of teachers have a profound impact on students. People's outlook on life, world outlook and qualities are critically shaped during the period of undergraduate study [6]. Teachers should always strictly demand themselves and enrich themselves to ensure the smooth implementation of high-quality aesthetic education courses.

\subsection{Organizing Various Aesthetic Education Cultural Activities}

The healthy growth of college students is inseparable from a favorable campus environment. A good campus environment will invisibly enhance the aesthetic taste and level of students. Representing a university's school-running philosophy as well as its direction regarding the training of talents, campus cultural activities are the central link in the construction of campus culture and an important symbol of the university's image.

Confucius said, "To be fond of knowledge is better than merely to acquire it; to take delight in it is still better than merely to be fond of it." Indeed, interest is the best teacher. The development level of aesthetic education is directly related to the development level of the comprehensive quality of contemporary college students. As an important approach to shaping the healthy personality of college students, aesthetic education occupies an extremely important position in college education.

Education is a long-standing cause that cannot be accomplished overnight. As an important part of college education, aesthetic education will definitely experience various ups and downs in the course of its development. As front-line educators, we should implement every detail of aesthetic education to enable college students to perceive, appreciate and create beauty incessantly.

\section{Acknowledgments}

Fund Project: Anhui Provincial Quality Engineering Project (2018JYXM0704); Quality Engineering Project of Bengbu University (2018JYXMW8); College Students' Innovative Entrepreneurial Training Plan Program of Anhui Province (201811305069)

\section{References:}

1. Xu Xiaoya. On the Impact of Aesthetic Education on the Humanistic Spirit of Contemporary College Students[J]. Folk Art and Literature, 2010 (18): 127-128.

2. Zhang Huan. The Research on the Promotion Strategy of College Students' Aesthetic Education from the Perspective of Media[D]. Wuhan: Wuhan University of Technology, 2017: 101-103.

3. Wang Lieying. A View on the Status and Function of
CAI Yuan- pei's Aesthetic Education Thought in Educating Perfect Character[J]. Journal of Zhanjiang Normal College, 2015 (08): 102-105.

4. He Yuanchun. Research on the Diversification of Physical Education and Health Curriculum Model[J]. Journal of Beijing Sport University, 2004 (02): 236-237.

5. Hou Haizhen. On How to Develop Aesthetic Education in English Teaching[J]. The New Generation, 2018 (03): 16.

6. Yao Zhipeng. College Students' Psychological Health as Seen from Quality Education[J]. Journal of Shanghai Business School, 2008: 98-100. 